\title{
A
}

Acta HealthMedica

Volume 2, Issue 2, April-June 2017, Pages: 166, DOI: http://dx.doi.org/10.19082/ah166

\section{CODING DATA QUALITY AT THE URMIA CANCER REGISTRY SYSTEM: EVALUATION OF COMPLETENESS, VALIDITY AND TIMELINESS}

\author{
Mohamad Jebraeily ${ }^{1,2}$, Habibollah Pirnejad ${ }^{1,2}$, Siamak Naji ${ }^{2,3}$
}

1: Department of Health Information Technology, Urmia University of Medical Sciences, Urmia, Iran

2: Urmia cancer registry center

3: Department of Pathology, Urmia University of Medical Sciences, Urmia, Iran

\section{Correspondence:}

Mohamad Jebraeily, Department of Health Information Technology, Urmia University of Medical Sciences, Urmia, Iran. Tel: +98. 4432752305, Fax: +98.4432752305, E-mail: jabraeili.m@umsu.ac.ir

\section{TYPE OF ARTICLE: CONFERENCE ABSTRACT}

\begin{abstract}
Introduction: cancer registry is an information system designed for the collection, storage, management, and analysis of data from a variety of sources such as pathology reports, medical records and death certificates. The value of the cancer registry and its ability to affect cancer prevention, control, or treatment programs rely on quality of its data. It is critical that data collected in cancer registry is classified according to ICD-O-3 for coding the primary site, histology, behavior, and grade of cancer. The evaluation of coding data quality is one of the most important for measuring data quality in a cancer registry. The purpose of this study was evaluation of coding data quality at the Urmia cancer registry system (UCRS).

Methods: In October 2016, we conducted a retrospective evaluation of coding data quality of UCRS based CanReg5 coding systems. We randomly sampled approximately 2,500 total registry cases. Three coder experts not associated with the UCRS were used in the evaluation of coding data quality based on three important components: completeness, validity and timeliness.

Results: The rate of completeness of coding data in topography, morphology and behavior were $95.26 \%, 93.91 \%, 91.56 \%$, respectively. The validity of coding for topography was $82.2 \%$ and also at the fourth digit, $90.68 \%$ were coded as unspecified sub-sites. The validity of coding for morphology was $87.46 \%$ and behavior $91.45 \%$. Only $63 \%$ of the registry cases complied with timeliness of coding. Conclusion: Although completeness of coding data at the UCRS is a good standard, its validity and timeliness of coding have some problems. For improving coding quality, coders must be trained and adhere to standardized coding rules. It seems essential for continuous and systematic evaluation of data quality used to code entry automated systems.
\end{abstract}

KEYWORDS: Cancer registry, Coding data quality, Completeness, Validity, Timeliness.

\footnotetext{
Abstracts of First National Congress of Medical Informatics, Mashhad, Iran, February 2017

(C) 2017 The Authors. This is an open access article under the terms of the Creative Commons Attribution-NonCommercialNoDerivs License, which permits use and distribution in any medium, provided the original work is properly cited, the use is non-commercial and no modifications or adaptations are made.
} 